\title{
Obesity in Prader-Willi syndrome: physiopathological mechanisms, nutritional and pharmacological approaches
}

\author{
G. Muscogiuri $^{1,2}$ - L. Barrea ${ }^{1,3} \cdot$ F. Faggiano $^{4} \cdot$ M. I. Maiorino $^{5} \cdot$ M. Parrillo $^{6} \cdot$ G. Pugliese $^{1} \cdot$ R. M. Ruggeri ${ }^{7}$. \\ E. Scarano ${ }^{1} \cdot$ S. Savastano ${ }^{1} \cdot$ A. Colao ${ }^{1,2}$ on behalf of RESTARE
}

Received: 12 January 2021 / Accepted: 8 April 2021 / Published online: 23 April 2021

(c) The Author(s) 2021

\begin{abstract}
Prader-Willi syndrome (PWS) is a genetic disorder caused by the lack of expression of genes on the paternally inherited chromosome 15q11.2-q13 region. The three main genetic subtypes are represented by paternal 15q11-q13 deletion, maternal uniparental disomy 15, and imprinting defect. Clinical picture of PWS changes across life stages. The main clinical characteristics are represented by short stature, developmental delay, cognitive disability and behavioral diseases. Hypotonia and poor suck resulting in failure to thrive are typical of infancy. As the subjects with PWS age, clinical manifestations such as hyperphagia, temperature instability, high pain threshold, hypersomnia and multiple endocrine abnormalities including growth hormone and thyroid-stimulating hormone deficiencies, hypogonadism and central adrenal insufficiency due to hypothalamic dysfunction occur. Obesity and its complications are the most common causes of morbidity and mortality in PWS. Several mechanisms for the aetiology of obesity in PWS have been hypothesized, which include aberration in hypothalamic pathways of satiety control resulting in hyperphagia, disruption in hormones regulating appetite and satiety and reduced energy expenditure. However, despite the advancement in the research field of the genetic basis of obesity in PWS, there are contradictory data on the management. Although it is mandatory to adopt obesity strategy prevention from infancy, there is promising evidence regarding the management of obesity in adulthood with current obesity drugs along with lifestyle interventions, although the data are limited. Therefore, the current manuscript provides a review of the current evidence on obesity and PWS, covering physiopathological aspects, obesity-related complications and conservative management.
\end{abstract}

Keywords Prader-Willi syndrome $\cdot$ Obesity $\cdot$ Hyperphagia $\cdot$ Diabetes mellitus

G. Muscogiuri

giovanna.muscogiuri@unina.it

1 Sezione di Endocrinologia, Unità di Endocrinologia, Dipartimento di Medicina Clinica e Chirurgia, Università Federico II di Napoli, Via Sergio Pansini 5, 80131 Naples, Italy

2 Cattedra Unesco "Educazione alla Salute e allo Sviluppo Sostenibile", Università "Federico II" di Napoli, Naples, Italy

3 Dipartimento di Scienze Umanistiche, Università Telematica Pegaso, Napoli, Italy

4 Ambulatorio Diabetologia, Asp Cosenza, Cosenza, Italy

5 Unit of Endocrinology and Metabolic Diseases, University of Campania “Luigi Vanvitelli”, Naples, Italy

6 Endocrinology and Metabolic Disease, AORN S. Anna S. Sebastiano Caserta, Caserta, Italy

7 Department of Clinical and Experimental Medicine, University of Messina, Messina, Italy

$\begin{array}{ll}\text { Abbreviations } \\ \text { PWS } & \text { Prader-Willi syndrome } \\ \text { BMI } & \text { Body mass index } \\ \text { GH } & \text { Growth hormone } \\ \text { MR } & \text { Magnetic resonance } \\ \text { AG } & \text { Acylated ghrelin } \\ \text { UAG } & \text { Unacylated ghrelin } \\ \text { NPY } & \text { Neuropeptide Y } \\ \text { SSA } & \text { Somatostatin analogue } \\ \text { PP } & \text { Pancreatic polypeptide } \\ \text { PYY } & \text { Peptide YY } \\ \text { GHD } & \text { Growth hormone deficiency } \\ \text { EE } & \text { Energy expenditure } \\ \text { T2DM } & \text { Type 2 diabetes mellitus } \\ \text { HOMA-IR } & \text { Homeostasis model assessment index } \\ \text { HbA1c } & \text { Glycosylated hemoglobin } \\ \text { OGTT } & \text { Oral glucose tolerance test } \\ \text { GLP-1RAs } & \text { Glucagon-like peptide-1 receptor agonists } \\ \text { DPP-4 } & \text { Dipeptidyl peptidase-4 }\end{array}$




$\begin{array}{ll}\text { SGLT2 } & \text { Sodium-glucose co-transporter-2 } \\ \text { GLP-1 } & \text { Glucagon-like peptide 1 } \\ \text { HDL } & \text { High-density lipoprotein } \\ \text { LDL } & \text { Low-density lipoprotein } \\ \text { VFA } & \text { Visceral fat area } \\ \text { OSAS } & \text { Syndrome of sleep apnea } \\ \text { LC } & \text { Low carbohydrate } \\ \text { LF } & \text { Low fat } \\ \text { HQ } & \text { Hyperphagia Questionnaire } \\ \text { POMC } & \text { Pro-opiomelanocortin } \\ \alpha-M S H & \alpha \text {-Melanocyte-stimulating hormone } \\ \text { ARC } & \text { Arcuate nucleus } \\ \text { FDA } & \text { Food and Drug Administration } \\ \text { DHK } & \text { Dykens Hyperphagia Questionnaire } \\ \text { SG } & \text { Sleeve gastrectomy } \\ \text { MGB } & \text { Mini gastric bypass }\end{array}$

\section{Introduction}

Prader-Willi syndrome (PWS) is a complex multisystem disorder that is caused by the lack of expression of paternally active genes in the PWS critical region on chromosome 15 (15q11.2-q13). Subjects with PWS are characterized by short stature, several endocrine diseases such as hypogonadism, growth hormone/insulin-like growth factor-I axis dysfunction, hypothyroidism, central adrenal insufficiency, dysmorphic features, scoliosis, osteoporosis, mental retardation, and behavioral and psychiatric diseases. One of the main characteristics of PWS is severe obesity, whose prevalence varies according to age. Indeed, the prevalence of overweight and obesity in PWS is around $40 \%$ in children and adolescents [35], while this percentage tends to increase ranging from 80 to $90 \%$ in adulthood $[52,104]$. Although subjects with PWS have poor feeding and appetite in infancy, they developed uncontrolled appetite leading to weight gain after 3 years. It is noteworthy to observe that obesity in subjects with PWS has different characteristics than simple obesity [25]. Lean body mass is lower while fat mass is higher in subjects with PWS compared with subjects with simple obesity having similar body mass index (BMI) $[14,33]$. Subjects with PWS showed lower visceral adiposity compared to subjects with simple obesity and this could account for the higher insulin sensitivity detected in subjects with PWS [33] and less prevalence of dyslipidemia [33]. Although subjects with PWS seem to develop less frequent cardiovascular risk factors than subjects with simply obesity, some case reports of cardiovascular events have been reported mostly at a young age $[72,89]$. Although the milestone of the treatment of obesity in PWS is the prevention that could occur thanks to growth hormone $(\mathrm{GH})$ therapy and lifestyle interventions started in childhood [32], nutritional interventions along with the use of current antiobesity drugs provide evidence to be effective in adult subjects with obesity [44]. Therefore, the current manuscript aims to provide an overview of the current evidence on obesity in PWS, starting from a physiopathological point of view to obesityrelated complications and conservative management.

\section{Pathophysiology of obesity}

Obesity represents a hallmark of the disease and a major cause of morbidity and mortality, along with its complications in PWS [82]. Obesity in subjects with PWS occurs through different mechanisms summarized in Fig. 1.

\section{Nutritional phases}

Obesity develops starting from the second year of life, after an initial phase of poor feeding [79]. A gradual shift occurs over several nutritional phases through which subjects with PWS typically progress [25, 79]. Before birth, decreased fetal movements and growth restriction are observed with lower birth weight than siblings (phase 0 ). In early infancy (phase 1), hypotonia, poor suck and failure to thrive led to poor feeding and reduced appetite initially (0-9 months of age); from 9 to around 24 months of life, both feeding and appetite improve and weight increases at a normal rate. Starting from 2 years (phase 2), patients begin to gain weight due to a progressive increase in appetite and food interest. Hyperphagia, lack of satiety and obesity become prominent by school age (median age of onset: 8 years) and predominate during childhood (phase 3 ) through adulthood, although most but not all adults may develop satiety and resolution of food seeking (phase 4).

\section{Hypothalamic regulation of satiety}

Despite the exact mechanisms remain to be fully elucidated, the development of obesity is mainly related to dysfunction in the hypothalamic satiety centre and its hormonal regulatory circuitry, affecting food intake and energy expenditure. Disruption in the hypothalamic pathways of satiety control results in persistent and insatiable appetite, hyperphagia and hunger-related eating behaviours. Aggressive and obsessive food seeking and storage, eating of inedibles, stealing of food or money to buy food are common among subjects with PWS, along with behaviour with features of autism spectrum disorder (controlling and manipulative behaviour, compulsivity, and difficulty with changes in routine), which favours abnormal eating [66, 79, 82].

Alterations in several brain areas (hypothalamus, amygdala, hippocampus, orbitofrontal and medial prefrontal cortex) play a crucial role in the abnormal food intake regulation in PWS. Functional magnetic resonance (MR) imaging 


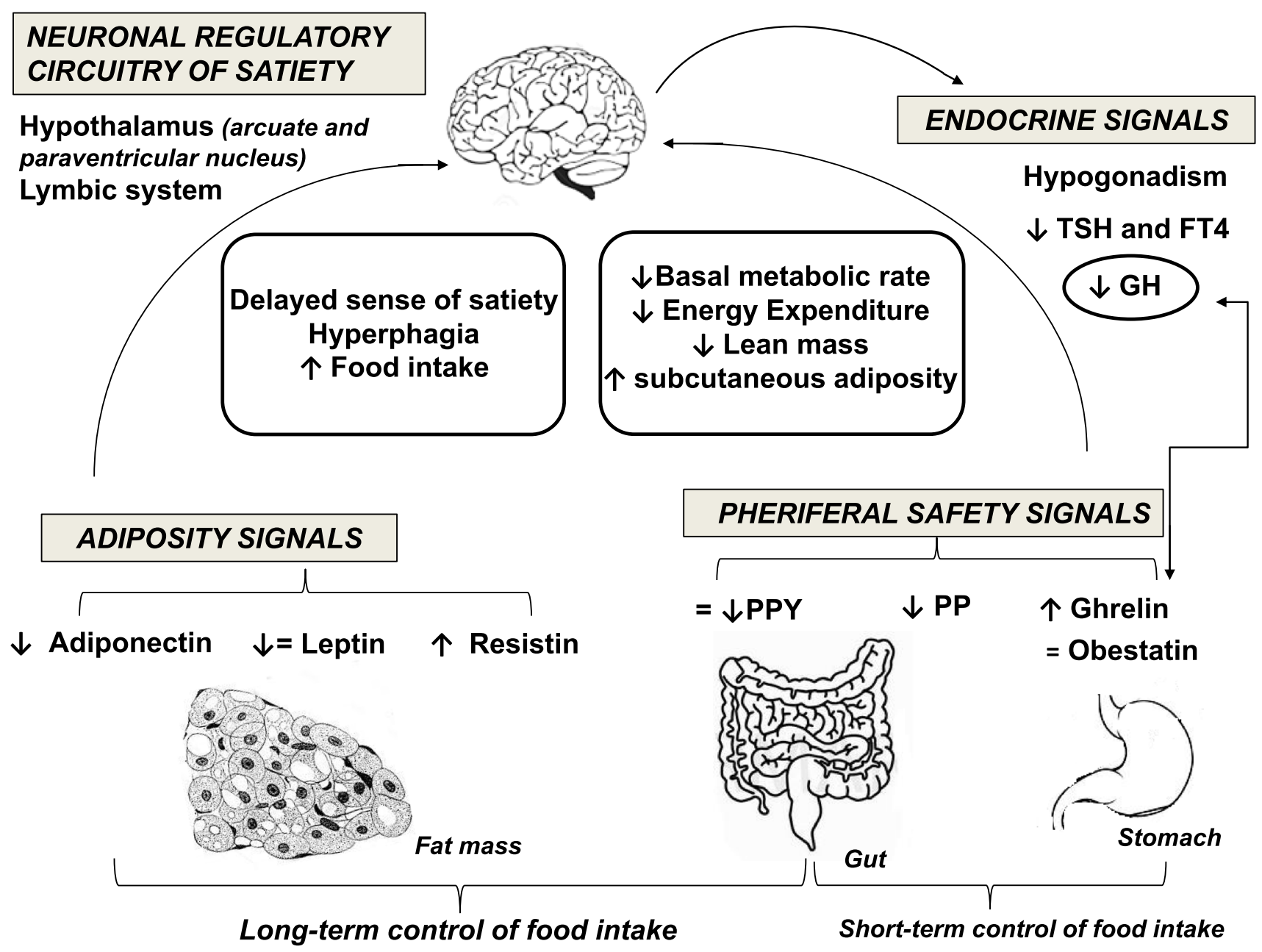

Fig. 1 Mechanisms involved in the development of obesity in PraderWilli syndrome (PWS). The proposed mechanisms include disruption in limbic-hypothalamic pathways of satiety control resulting in hyperphagia, alterations in hormones regulating food intake, reduced energy expenditure. Persistent increase in plasma ghrelin results in increased appetite via the central regulating mechanisms in the hypothalamus and increased food intake. Decreased plasma PP and PYY contribute to failure to satiety control. The role of leptin is still under

demonstrated pre-meal higher activity in reward/limbic regions (nucleus accumbens, amygdala) and lower activity in the hypothalamus and hippocampus in response to food (vs non-food) in subjects with PWS compared to subjects with obesity non-PWS. Mostly, subjects with PWS exhibited a greater post-meal stimulation of food activation centres in the limbic and paralimbic region (hypothalamus, amygdala, hippocampus) and a lower activation in cortical inhibitory regions (orbitofrontal cortex, medial prefrontal cortex) [59, $60,115]$. This abnormal response is even higher for highcalorie vs. low-calorie foods [36]. Additionally, reduced functional connectivity between the ventral striatum and the limbic structures (hypothalamus and amygdala) was reported in subjects with PWS and it was correlated to obsessive investigation, as overall evidence suggests that leptin is unlikely to be misregulated in PWS obesity. Deficiency of GH and hypogonadism result in reduced muscle mass and increased body fat. Central hypothyroidism may contribute to reduced energy expenditure. Higher levels of ghrelin, adiponectin and resistin are associated with increased adiposity. $G H$ growth hormone, $P Y Y$ peptide $Y Y, P P$ pancreatic polypeptide, $T S H$ thyroid-stimulating hormone

eating behaviour [95]. These brain functional studies clearly indicate that disruption of hypothalamic control of satiety, dysfunction in the associated reward circuitry regions and impairment in inhibitory control areas jointly contribute to extreme hyperphagia and obesity in PWS.

\section{Alterations in hormones regulating food intake and adiposity}

Several orexigenic and anorexigenic hormones are deemed to be involved in the development and maintenance of obesity in PWS, through appetite dysregulation. 
- Ghrelin, a potent orexigenic hormone, is secreted by the stomach during fasting and starvation and its circulating levels are suppressed by food intake. Among the numerous physiological effects exerted, ghrelin increases appetite via central regulating mechanisms in the hypothalamus, stimulates GH secretion, regulates energy homeostasis and brown fat thermogenesis and also stimulates gastric emptying [67]. Most [17, 21, 34, $39,69,94,96]$, but not all [37] studies reported persistently increased ghrelin levels in subjects with PWS at any age compared with BMI-, age- and sex-matched control children. Additionally, ghrelin levels remained elevated and did not appropriately suppress after eating in subjects with PWS compared to non-PWS controls with obesity [53]. The highest levels of ghrelin were found in the youngest children, even preceding the onset of increased appetite and obesity in PWS [45]. It has been hypothesized that the increase in circulating ghrelin levels occurs early in infancy, in response to difficulties to thrive and poor feeding. Persistent hyper-ghrelinemia promotes hyperphagia and obesity later in childhood [58], even if some Authors argued against a direct role of high ghrelin levels in the hyperphagia of PWS [69]. Recently, it has been demonstrated in mice that neonatal ghrelin programs the development of hypothalamic feeding circuits. Indeed, early postnatal chronic administration of ghrelin impairs the normal development of the hypothalamus, causes metabolic dysfunction and predisposes to obesity later in life [107]. In 2016, Beauloye et al. demonstrated that subjects with PWS in early infancy had normal acylated ghrelin (AG) levels, but high unacylated ghrelin (UAG) levels, confirming that total ghrelin is elevated at this age. Such an increase in total ghrelin was mainly due to the inactive form UAG, thus explaining poor appetite in early infancy, as opposed to that found later in life, when subjects with PWS display obesity and hyperphagia [12]. A subsequent study found that circulating ghrelin levels were elevated in children and adult subjects with PWS compared to both lean and obese controls as a result of increased active AG, whereas UAG was relatively low. The obese controls displayed the same relative deficit of UAG, but had lower levels of total ghrelin and lower AG/UAG compared to the lean controls [68]. Tauber and coworkers, who published the first study demonstrating that hyperghrelinaemia starts early in life, prior to hyperphagia and obesity [39], concluded for an impaired development of the ghrelin system in subjects with PWS, starting with excessive UAG, which then decreases, followed by an excessive increase in AG and a relative deficit in UAG. Subsequently, the AG/UAG ratio in subjects with PWS was significantly higher than in controls when the patients displayed hyperphagia, indicating an increase of this AG/UAG ratio throughout the nutritional phases. The ghrelin system is differently impaired at different ages and this impaired switch in the ghrelin system would explain the early excessive weight gain and subsequent obesity with hyperphagia observed in PWS [111, 112]. However, several groups have shown that pharmacological reduction of ghrelin to normal levels in PWS, using either short or long-acting somatostatin analogue (SSA), did not improve feeding behaviour and did not reduce the appetite of children and adults with PWS nor affect the weight $[55,112]$. Since the anorexigenic circuits related to ghrelin are disrupted early in life in PWS, it is conceivable that decreasing the level of ghrelin is not sufficient to reset the system in child, adolescents and adults. Finally, independent of its orexigenic effects, ghrelin stimulates adipose tissue lipogenesis and inhibits lipolysis, maybe contributing to increased adiposity in PWS [91].

- Obestatin is produced in the stomach by post-translational modification of ghrelin. In contrast to ghrelin, obestatin suppresses food intake, inhibits gastric emptying and decreases weight gain [114]. No significant difference has been reported in plasma obestatin levels between PWS and non-PWS subjects with obesity [90].

- Pancreatic polypeptide (PP) and peptide YY (PYY) are anorexigenic hormones released by the intestine postprandially to induce satiety and inhibit eating [105]. PP levels were reduced in children with PWS [45], while PYY levels were found to be either reduced [21] or increased [62] in subjects with PWS compared to either obese or not obese controls. Mostly, post-prandial PYY levels were similar in children with PWS and controls [17]. In addition, no differences between subjects with or without PWS emerged in the pattern of expression of ghrelin and PYY genes and their receptors in the brain [109].

- Leptin is a peptide produced by adipose tissue and is involved in the regulation of appetite and fat storage. Released by adipocytes in response to satiety signals, it reduces food intake and energy metabolism by inhibiting neuropeptide Y (NPY) neurons in the arcuate nucleus [92]. In the study by Goldstone et al., fasting leptin levels were significantly higher in subjects with PWS ( $n=42$, aged 7 months- 5 years) compared to age-, sex- and BMImatched controls $(n=9)$, without any significant relationship with age, BMI and eating behaviour [45]. However, most studies failed to find any difference in leptin levels between subjects with or without PWS and obesity, as leptin levels were consistent with increased adiposity associated with obesity irrespective of aetiology [22, 47, $73,85]$. Thus, leptin is unlike to be misregulated in PWS.

- Adiponectin is another peptide produced by adipose tissue and plays a role in regulating adiposity. Serum adiponectin levels were found to be significantly lower 
in subjects with PWS compared with lean ones and significantly higher compared with obese controls [16]. Adiponectin is also associated with increased insulin sensitivity in subjects with PWS [54]. Recent evidence indicates that subjects with PWS are less likely to develop diabetes than non-PWS ones with comparable BMI [49]. This may be due to the altered fat distribution in subjects with PWS, resulting in greater adiponectin production than comparison subjects.

- Serum resistin and resistin mRNA expression in adipose tissue was significantly higher in subjects with PWS, compared with both healthy lean controls and subjects with obesity and without PWS. Moreover, higher levels of resistin were associated with lipogenesis in subjects with PWS and obesity, whereas no significant association was found between resistin and insulin resistance [88].

\section{Endocrine dysfunctions}

Multiple endocrine abnormalities due to hypothalamic dysfunction are quite common in subjects with PWS and may represent factors contributing to abnormal body weight and composition. Growth hormone deficiency (GHD) is associated with decreased lean mass, increased fat mass (mainly truncal fat with increased waist/hip ratio), poor muscle tone and strength, decreased movements and reduced energy expenditure and exercise tolerance. In both children and adults with PWS, GH treatment reduced BMI and improved body composition, increasing lean mass and reducing fat mass. Also, muscle tone, exercise endurance and energy expenditure improved with $\mathrm{GH}$ treatment $[8,71,106]$. Moreover, studies following patients for 12-24 months after the cessation of GH replacement have shown a progressive increase in BMI and a tendency towards an increase in visceral adipose tissue [86]. Hypogonadism, occurring in almost $100 \%$ of subjects with PWS, is also associated with increased BMI and abnormal body composition (reduced muscle mass and increased fat mass) [82]. Similarly, the peripheral effects of thyroid hormone deficiency affect body composition, contributing to reducing energy expenditure. Indeed, subjects with PWS exhibit a lower amount of lean body mass and a higher level of fat mass compared to obese subjects with similar BMI [74]. The decrease in muscle mass is the result of endocrine dysfunctions (GH deficit and hypogonadism), severe muscle hypotonia, lower physical activity, behavioral issues and reduced both resting and activity energy expenditure (EE), despite a normal relationship between fat-free mass and EE [14]. The distribution of fat and lean mass differ between body sites (e.g., between lumber and spine areas and the hips and thighs). The excessive fat mass in subjects with PWS is typically distributed to the trunk and to the proximal extremity of the limbs, with a lower trunk-to-appendicular fat mass ratio and prevalent subcutaneous and less visceral fat accumulation. According to the reduction in visceral adiposity, preserved insulin sensitivity and lower metabolic consequences are observed in subjects with PWS in comparison to BMI-matched obese controls $[18,48,82,108]$. Possible explanations could be the prevalent subcutaneous and less visceral fat accumulation, higher ghrelin and adiponectin levels as well as lower GH hormone levels [48, 82].

\section{Obesity-related comorbidities}

\section{Type 2 diabetes mellitus}

PWS is often complicated by glucose intolerance and the development of diabetes mellitus. The reported prevalence of diabetes in subjects with PWS ranges from 7 to $24 \%$, with higher rates in obese adults after the 5th decade and lower rates in prepubertal age [35, 104]. Moreover, a retrospective study revealed an earlier onset of diabetes (median age of 15 years) in 65 Japanese subjects with PWS, maybe due to the higher rate of metabolic disorders in Asian diabetic children than in Caucasians [113]. The most frequent form of diabetes in PWS patients is represented by type 2 diabetes mellitus (T2DM) [35, 104, 113]. Obesity and weight gain are well-known risk factors for the development of insulin resistance and T2DM [38]. However, the role of overweight/ obesity in the pathogenesis of T2DM in subjects with PWS remains controversial. Both cross-sectional [13] and longitudinal [110] studies showed that the distribution of fat in subjects with PWS is predominantly subcutaneous, as compared with individuals with non-syndromic obesity, with lower levels of insulin resistance. Moreover, subjects with PWS showed lower fasting insulin levels despite severe obesity grade [70]. In this study, Lacroix et al. compared metabolic profile and fat distribution in 42 PWS adults with matched subjects with primary obesity reporting that the PWS group had a lower percentage of trunk fat mass and a better metabolic profile, in particular a lower insulin resistance assessed by HOMA index than the control group. It has been widely demonstrated that PWS subjects showed a state of relative hypoinsulinemia, without the expected insulin resistance, despite their severe obesity. The reasons for the lacking onset of insulin resistance sensitivity in PWS patients could be due to a small amount of visceral fat compared to total adiposity, an impaired GH secretion and higher levels of ghrelin considering the degree of obesity [30]. At the early onset of T2DM, subjects with PWS are generally asymptomatic or may present the classic Hippocrates' triad of diabetic symptoms (polyuria, polydipsia and unexpected weight loss) [11]. Periodic and regular evaluation of glucose levels, glycosylated hemoglobin (HbA1c), lipid profile and blood pressure should be recommended in all subjects with PWS 
since childhood [30]. An oral glucose tolerance test (OGTT) should be performed in subjects with PWS and obesity at pubertal and adult age. Moreover, both glucose and insulin levels should always be evaluated before and after starting GH therapy, as GH has counter-regulatory effects on glucose metabolism [30]. The diagnostic criteria for diabetes and prediabetes (i.e., impaired fasting glucose) to be followed for subjects with PWS are the same used for the general population [7]. In the long-term, subjects with PWS and T2DM seem to be less prone to develop diabetic-related complications as compared to general diabetic patients [11]. However, at the time of diagnosis of T2DM and thereafter, screening for microvascular complications (retinopathy, nephropathy and neuropathy), hypertension and cardiovascular disease should be carried out annually. The primary goal of the treatment of T2DM in subjects with PWS is to improve the quality of life, while reducing weight and achieving an optimal glycaemic control. The first-line therapy is based on a restriction of caloric intake and regular exercise to promote weight loss and improve glycemic control [76]. Pharmacological strategies for T2DM in subjects with PWS do not differ from those followed for the general population [6]. Metformin represents the first-line glucose-lowering agent to choose in combination with lifestyle modification since it helps to reduce satiety and improve insulin sensitivity, promoting weight loss. Alpha-glucosidase inhibitor, acarbose, may be a promising alternative option. It is associated with reduction of body weight, post-prandial glucose levels and daily insulin doses. In a study on Japanese population, alpha-glucosidase inhibitors were used by more than 50\% of subjects with PWS and T2DM [113]. On the other hand, thiazolidinediones, sulfonylureas and insulin regimens are not recommended due to weight gain and risk of hypoglycemia. Glucagon-like peptide-1 receptor agonists (GLP-1RAs) and dipeptidyl peptidase-4 (DPP-4) inhibitors represent both valid and effective options to enhance weight management and HbA1c control in subjects with PWS [44, 56]. Data regarding the recent and innovative Sodium-glucose cotransporter-2 (SGLT2) inhibitors are rather scarce. Use of canagliflozin on a 40-years-old diabetic woman with PWS resulted in an improvement of $\mathrm{HbA} 1 \mathrm{c}$ and in a decrease of body weight [65]. Currently, the evidence regarding the combined use of GLP-1 agonists and SGLT-2 inhibitors in the treatment of type 2 diabetes mellitus in PWS is limited to some case reports. In a 20-year-old woman with PWS, the addition of SGLT2 inhibitor, empagliflozin (10 mg/day) to existing liraglutide therapy resulted in significant improvements in both weight and glycemic control: a weight loss of approximately $5.5 \mathrm{~kg}(7.4 \%)$ was achieved during the subsequent 5 months without altering dietary intake and $\mathrm{HbA} 1 \mathrm{c}$ level notably improved from 9.2 to $7.2 \%$ [101]. In an adolescent with T2DM and PWS the add-on of Metformin to different insulin regimens or Liraglutide did not improve glucose levels. Liraglutide and Empaglifozin (SGLT-2 inhibitor) therapy used in combination were well tolerated and rapidly normalized blood glucose and $\mathrm{HbA} 1 \mathrm{c}(48 \mathrm{mmol} /$ mol) which was sustained after 6 months of treatment [23]. Insulin therapy should be considered when oral glucoselowering agents are no longer effective in glycaemic control or when there is evidence of insulin deficiency (ketoacidosis and unexplained weight loss). Moreover, in case of T2DM with serious obesity morbidities, bariatric surgery should be an alternative worth considering to achieve a rapid and beneficial weight loss [30]. It helps to reduce ghrelin levels and increase Glucagon-like peptide 1 (GLP-1) secretion, even if long-term effects on weight loss are less effective than in non-syndromic obesity. It should be considered only in selected subjects with PWS on psychological support when other therapeutic strategies have failed or are not available.

\section{Dyslipidemia}

Few studies investigated dyslipidemia in subjects with PWS [20, 48, 54, 108]. Butler et al. [20] enrolled 26 subjects with PWS (14 males/12 females, mean age $18.9 \pm 7.0$ years) and 32 subjects with obesity ( 6 males/26 females age $23.6 \pm 6.6$ years). No significant differences were found in terms of triglycerides $(96.2 . \pm 67.0$ vs $97.3 \pm 61.8 \mathrm{mg} / \mathrm{dl})$, total cholesterol $(180.6 \pm 46.5 \mathrm{vs} 196.1 \pm 53.9 \mathrm{mg} / \mathrm{dl})$, high-density lipoprotein (HDL) cholesterol $(42.7 \pm 12.9$ vs $45.7 \pm 14.2 \mathrm{mg} / \mathrm{dl})$ and Low-density lipoprotein (LDL) cholesterol (136.1 \pm 32.6 vs $141.4 \pm 62.1 \mathrm{mg} / \mathrm{dl}$ ) levels between subjects with PWS and subjects with obesity, respectively. Thus, the authors conclude that plasma lipid levels are not altered in subjects with PWS. Similar findings were found by Haqq et al. [54] that assessed lipid profile in 14 subjects with PWS (median age and BMI $Z$ score: 11.4 and 2.15 years, respectively), 14 age and BMI matched children with obesity (median age and BMI Z score 12.0 and 2.35 years, respectively) and 14 age-matched lean children (median age and BMI Z score 12.3 and -0.6 years, respectively). Fasting plasma total and LDL cholesterol were comparable between the three groups. As expected, children with obesity showed 38\% lower HDL cholesterol levels $(p<0.001)$ and twofold higher plasma triglycerides $(p<0.001)$ compared to lean children. No significant differences were detected between children with PWS and lean children, while they showed significantly higher HDL and lower triglycerides compared to children with obesity [54]. Talebizadeh and Butler [108] compared 37 subjects with PWS (age $22.7 \pm 9.5$ years, BMI $36.5 \pm 4.3 \mathrm{~kg} / \mathrm{m}^{2}$ ) with 18 subjects with obesity (age $25.9 \pm 13.3$ years, BMI: $38.1 \pm 5.8 \mathrm{~kg} / \mathrm{m}^{2}$ ). No statistical differences were detected in plasma cholesterol, whereas fasting triglycerides were lower in the PWS group $(158.4 \pm 90.3$ vs $252.4 \pm 186.7 \mathrm{mg} / \mathrm{dl})$. In this study, the authors also evaluate regional fat distribution using T1 weighted MR images and grouped subjects 
according to intra-abdominal visceral fat area (VFA) higher or less than $130 \mathrm{~cm}^{2}$. In the control group with obesity, no significant differences in plasma lipids were detected in the subjects with VFA $\geq 130 \mathrm{~cm}^{2}$ compared to the subjects with VFA $<130 \mathrm{~cm}^{2}$. However, in PWS group with high intra-abdominal VFA (VFA $>130 \mathrm{~cm}^{2}$ ) fasting triglycerides were significantly increased compared with the subjects with PWS with VFA $<130 \mathrm{~cm}^{2}$, but no differences in total cholesterol were found. These data suggest that in subjects with PWS adiposity localized in the abdominal region, visceral fat compared with subcutaneous fat, which is associated with high triglyceride plasma levels [108]. In conclusion, although the studies on dyslipidemia in PWS are few, most of them agree that subjects with PWS tend to have a lipid profile similar to lean subjects. This could be explained by the fact that subjects with PWS have less visceral fat content compared to BMI-matched subjects with obesity and this could preserve the lipid profile by the detrimental effect of fat in the context of this syndrome.

\section{Cardiovascular disease}

Due to the multiple presence of cardiovascular risk factors such as obesity, hypertension, T2DM, syndrome of sleep apnea (OSAS), and low-grade chronic inflammation [9, 63] subjects with PWS are expected to be at risk of developing cardiovascular diseases. A nationwide cohort study carried out in Denmark in 155 subjects with PWS that were followed-up from birth through to the first occurrence of an outcome of interest found an increased risk of myocardial infarction (RR: 7.2; 95\% CI 1.7-30.2) in these subjects compared to the general population [57]. However, cardiovascular diseases in PWS have been mostly detected in young age as reported in a 28-year-old woman with PWS that developed chest pain and loss of anterior $\mathrm{R}$ wave amplitude on the electrocardiogram [89]. A severe proximal stenosis of the left anterior descending artery with delayed antegrade flow together with antero-apical akinesia consistent with myocardial infarction has been detected at cardiac catheterization [89]. Also, an inferior wall myocardial infarction has been reported in 26-year-old white male with PWS and T2DM [72]. A graded exercise test using the Bruce protocol showed inferolateral ischemia. A subsequent cardiac catheterization showed severe, inoperable three-vessel coronary artery disease [72]. Although few cases of cardiovascular diseases have been reported in subjects with PWS, a screening and eventual treatment of cardiovascular risk factors in these patients is mandatory, mostly because cardiovascular events have been reported at a young age.

\section{Obesity prevention in PWS}

Obesity is one of the principal features of PWS, which is linked to morbidities (including T2DM, metabolic syndrome, OSAS, respiratory insufficiency, and cardiovascular disease) and premature mortality [31]. Thus, it is important to prevent obesity in the first years of life and to implement strategies that allow the control of caloric intake. Unfortunately, in subjects with PWS this is not very easy because they have low compliance to follow food restrictions and they tend to consume any type of food, even unconventional or with bad taste, to satisfy their insatiability. Therefore, the obesity prevention approach must be carried out at several levels with dietary, physical and behavior interventions. It is advisable to consult a nutritionist who can establish a specific program characterized by a correct caloric intake in the first months [31] of life followed by a low-calorie, well-balanced diet and close supervision to minimize food stealing [27, 76]. Physical activity and muscle force training need to be an important part of daily life in subjects with PWS of all ages. It has been demonstrated that young subjects with PWS engaged in less overall physical activity than subjects with obesity without PWS, on both weekends and throughout the week [26]. Probably this is due to the fact that subjects with PWS have less muscle mass and lower muscle tone than other children [26]. Therefore, interventions should integrate activities of different intensity, to motivate patients to follow exercise programs [97]. Moreover, it is recommended to start these programs in young infants, to provide skill acquisition and strength training to increase motor development [97]. It is necessary to educate subjects with PWS to manage anxiety and follow the recommended programs. To adhere to all the suggested recommendations (prescribed diet, eating routines, healthy eating behaviors, daily exercise), patients need to be supported by behavioral programs in which are included teachers, friends and family members [50]. At last, to prevent the development of obesity, GH treatment could have an important role. In subjects with PWS, GH has beneficial effects on body composition, basal energy consumption, muscle strength, exercise tolerance and decrease in free fat mass $[24,41,80,84]$ and many studies revealed that effects on body composition are greater in the first year of treatment $[33,35,43]$. In fact, one of the studies in which subjects with PWS received therapy for a long period [8] starting at the age of 3-7 years, reported that lean body mass significantly increased and fat $\mathrm{SD} \%$ significantly decreased in the first year of treatment, while no significant difference was observed in the subsequent years and at the end of the 8-year treatment period. Regarding BMI, values in PWS remained higher than normal children but 
were below that of non-treated children with PWS, thus suggesting that $\mathrm{GH}$ therapy could have a role in hindering obesity. However, it should be pointed out that response to GH therapy changes according to age of starting treatment. In a study that compared subjects with PWS receiving GH therapy (starting age 4-20 months) with those who did not, it was reported that the treated group had a lower body fat, increased muscle mass, better lipid profile and better motor function [24], thus suggesting that early treatment might explain the significant differences observed.

\section{Nutritional management of obesity in PWS}

Nutritionists play a major role in the management of obesity in PWS, considering that dietary restriction is one of the only successful treatments in the reduction and maintenance of body weight in this disease. Whereby, nutritionists as integral members of an interdisciplinary team must understand the complexity of this disease. Infants with PWS at birth have a normal length and are either normal weight or underweight $[14,46]$. However, the presence of hypotonia, which also affects the oral cavity, commonly leads to a poor sucking ability. This leads to failure to thrive, which represents the first stage of PWS throughout infancy. The nutritional goal for infants with PWS is to promote proper growth without leading to overweight or obesity. To do this, the infants with PWS should be kept between the 50th and 75th percentile of his/her weight for height [98]. Of interest, the basal metabolic rate, the minimum energy required to maintain vital body functions [93], in infants with PWS is slower than an infant without PWS, suggesting that infants with PWS require fewer calories than the healthy counterparts. In preschool and school-age children with PWS the guidelines recommend from 10 to $11 \mathrm{cal}$ per centimeter of length to keep the weight and 8 to $9 \mathrm{cal}$ per centimeter to reduce body weight [98]. For young children, the guidelines recommend from 600 to $800 \mathrm{cal}$ per day while for older children and adults from 800 to 1100 cal per day [19]. In addition, it is important in subjects with PWS to take a multivitamin, and above all take a vitamin D supplement if necessary, to compensate for the reduced intake of vitamins and minerals that may be suboptimal due to a restrictive diet $[10,98]$. When subjects with PWS develop obesity in adulthood, body weight should be assessed frequently and the total energy intake adjusted accordingly.

Currently, the best nutritional strategy in PWS subjects would appear a well-balanced low-calorie diet, in fact, in a study on 63 subjects with PWS, it has been reported that a balanced energy-restricted diet of approximately $30 \%$ fat, $45 \%$ carbohydrates (at least $20 \mathrm{~g}$ of fiber per day) and $25 \%$ protein, significantly improved both weight and body composition compared to a simple energy-restricted diet [78].
Some studies have evaluated the effect of low-carb diets in PWS subjects. In a clinical study, the efficacy and safety of the modified Atkins Diet for 4 months (low carbohydrate and high fat) was assessed in seven children with PWS ages 6-12 years who were overweight/obese; it was shown that only one patient lost $2.9 \mathrm{~kg}$ while the others did not change their weight. Positive effects on hyperphagia and behavior were subjectively reported by families [40]. Another study was carried out by Irizarry et al. to investigate the effect of different diets on hormonal and metabolic balance in PWS: eight PWS children (age 9-18 years) were randomized to consume either low-carbohydrate, high-fat (LC, 15\% carb; $65 \%$ fat; $20 \%$ protein) or low-fat, high-carbohydrate (LF, $65 \%$ carb, $15 \%$ fat, $20 \%$ protein) diets matched for calories and protein, during a first hospital admission and the second nutritional pattern during a subsequent admission, collecting blood samples after overnight fasting and $1 \mathrm{~h}$ after a mixed meal. It was observed that subjects consuming the LC diet had lower postprandial insulin concentrations, higher fasting GLP-1 and GIP concentrations, increased postprandial GLP-1 and reduced ratio of fasting ghrelin to GLP-1 compared to LF diet. Although further studies on a larger sample are needed, this evidence suggests that increases in GLP-1 with LC feeding and reductions in the ratio of ghrelin to GLP-1 might limit food intake and improve glycaemic control in PWS [64].

\section{Pharmacological treatment of obesity in PWS}

As extensively illustrated above, obesity in the subject with PWS seems to depend on pathophysiological mechanisms that are in part different from idiopathic obesity and, therefore, also regarding pharmacological therapy, it could benefit from some categories of drugs with mechanisms of action various and innovative. Metformin is an oral hypoglycaemic drug indicated in T2DM, but also used off-label in conditions of obesity and prediabetes [5]. Its mechanism of action is not fully known, although, in addition to the known insulin-sensitizing effect on the liver and muscle, it also appears to have an anorectic effect: central to the hypothalamic-pituitary circuits and peripheral due to increased secretion of GLP-1 from the intestine [75]. In a pilot study of 21 children and adolescents with PWS with insulin resistance and glucose intolerance on OGTT that started for this reason treatment with metformin, it has been observed an improvement of food-related distress and anxiety, evaluated by Hyperphagia Questionnaire (HQ) however without a reduction in body weight [77]. In addition, 7 out of 10 males had to stop metformin after 1-2 days for a marked deterioration in behavior. 
Naltrexone-bupropion combines drugs already tested for some decades in monotherapy and already in use for the treatment of alcohol and opioid dependence (Naltrexone), and major depression or smoking cessation (Bupropion). This combination determines a pharmacological hypothalamic synergistic mechanism in suppressing appetite and lowering body weight [51]. As for the mechanism of action, Bupropion is a mild inhibitor of dopamine and norepinephrine reuptake, which promotes the conversion of proopiomelanocortin (POMC) into $\alpha$-melanocyte-stimulating hormone $(\alpha-\mathrm{MSH})$, while Naltrexone prolongs its duration of action through retro-regulation of the $\mu$ opioid receptor, therefore Naltrexone/bupropion acts synergistically to activate POMC neurons in the hypothalamic, in particular in the neurons in the arcuate nucleus (ARC), resulting in appetite suppression [1]. There are two case reports on the use of naltrexone alone on a child and four adolescents, respectively $[15,116]$ : the first showed after 4 months of therapy a weak improvement in weight control and behavior, while the second, in which the treatment lasted one week, did not demonstrate a reduction in appetite, at least in the short term. The only described case of combination therapy with naltrexone/bupropion for 6 months showed an improvement of eating habits, without a significant reduction of BMI in an adolescent girl with PWS [61].

GLP-1RAs, such as exenatide and liraglutide, act by stimulating glucose-dependent insulin secretion and determining a decrease in appetite and weight, with protective effects on pancreatic $\beta$-cells and cardiovascular system, representing an effective drug for diabetes and obesity [28]. In a report of 6 cases of diabetic subjects with PWS treated with 1.2 to $1.8 \mathrm{mg}$ /day of liraglutide (4 patients) and $20 \mathrm{mg} /$ day of exenatide ( 2 patients), during the 24 months of treatment a tendency to decrease BMI, HbA1c, waist circumference and mean glycaemia was detected [44]. In a longitudinal study, the efficacy of exenatide therapy for 6 months in overweight or obese young adults with PWS was assessed and a reduction in appetite and an improvement in $\mathrm{HbAlc}$ without change in weight or BMI was observed [100]. Until now, no data are available on the use of dulaglutide or semaglutide in subjects with PWS which could be particularly useful in weight control.

Orlistat is a pancreatic lipase inhibitor useful for limiting fat absorption to up to $30 \%$ of ingested fat and approved for the treatment of obesity [99], however, studies evaluating the efficacy and safety in subjects with PWS are lacking. Moreover, regarding lorcaserin, a high-affinity selective agonist of the serotonin $2 \mathrm{C}$ receptor with a weak efficacy on weight loss [42], studies on subjects with PWS have not been performed. Moreover, in January 2020, Food and Drug Administration (FDA) requests the withdrawal of lorcaserin from the market because a safety clinical trial shows a possible increased risk of cancer during treatment with this drug.
Two different drugs: sibutramine, an unspecific inhibitor of serotonin and norepinephrine reuptake, and the rimonabant, an endocannabinoid CB 1 receptor antagonist, which act by reducing appetite and increasing energy expenditure, while appearing promising in subjects with PWS, have been withdrawn due to serious cardiovascular and psychiatric side effects, respectively, that emerged during clinical trials [81, 87].

Topiramate is an antiepileptic drug that acts as a modulator of $\mathrm{Na}+$ channels, GABA, and AMPA/kainate receptors, it is useful in the treatment of atypical psychoses of subjects with PWS and it is also known to affect food-seeking behavior [4]. A double-blind randomised placebo-controlled 8 -weeks trial was conducted on 62 subjects with PWS to study the efficacy and tolerance of the topiramate on behavioural disorders and it was observed that behaviour and severity scores evaluated by Dykens Hyperphagia Questionnaire (DHK) improved significantly more over time in topiramate group versus placebo group, with a significant dose-effect relationship, however, without a significant reduction of BMI [29].

Based on the numerous pathophysiological mechanisms proposed for obesity in PWS, there are currently several ongoing randomized clinical trials on different drugs such as diazoxide, beloranib, setmelanotide, intranasal oxytocin and oxytocin analogs, carbetocin and livoletide [31]. These molecules have different targets mostly acting on lipid metabolism and on the central circuits of hunger and satiety. In particular, livoletide, an unacylated ghrelin analog, after having demonstrated in a phase 2 randomized clinical trial a significant improvement in food-related behaviors [2], supported by a reduction in hunger, is currently under study in a phase 3 clinical trial. In the context of drugs being tested for the control of hyperphagia in PWS, the association of tesofensine (a presynaptic absorption inhibitor of noradrenaline, dopamine and serotonin) and metoprolol (a selective beta-blocker) is currently in phase $2 \mathrm{~b}$ of experimentation and has already shown promising results, in fact, in a phase 2a study involving 18 patients with PWS, this association reduced body weight, improved BMI and reduced hyperphagia to very low levels.

\section{Bariatric surgery in PWS}

Despite the number of cases of PWS subjects undergoing bariatric surgery did not report encouraging results in terms of weight loss and development of complications [103], more recent studies in which obsolete surgical techniques were avoided and mainly laparoscopic sleeve-gastrectomy (SG) and mini gastric bypass (MGB) were used [3, 83, 102], have shown that bariatric surgery can be a useful tool in the management of weight excess in selected cases of 
patients with PWS, with positive results in terms of weight loss and a reduced number of complications. One of the most controversial aspects remains PWS patients' compliance in the post-surgical frame time. Indeed, in the general population, a psychiatric assessment is carried out before bariatric surgery to investigate if the very same subjects are able to follow post-surgical indications to guarantee a result in terms of adequate weight loss and reduce the incidence of complications. Although most of the time PWS patients did not show a promising post-surgical compliance, bariatric surgery is the only possibility for weight loss A study on 60 American patients with PWS showed after 5 years from surgery a weight loss of only $2.4 \%$, significantly less than that observed in non-PWS subjects with obesity, however, as anticipated this data could be influenced by different types of surgery performed, some of which are now obsolete (54\% biliopancreatic diversion, $29 \%$ gastric bypass, $18 \%$ bioenteric intragastric balloon, $5.4 \%$ jejunoileal bypass, $3.6 \%$ gastroplasty, $3.6 \%$ vertical banded gastroplasty, $1.8 \%$ silicone band gastroplasty, and $1.8 \%$ truncal vagotomy) and that many subjects, 49 PWS patients, were lost to follow-up [103].

Instead, in a study of 24 adolescents, PWS compared to 72 non-PWS subjects matched for age, gender and BMI, all underwent a laparoscopic $\mathrm{SG}$, a reduction in BMI of $15 \mathrm{~kg} / \mathrm{m}^{2}$ at 1 year and $11 \mathrm{~kg} / \mathrm{m}^{2}$ at 5 years, respectively, was observed, no different than the non-PWS group, in the absence of re-hospitalization for complications during follow-up, suggesting that SG could be an effective and relatively low-risk procedure in these subjects [102]. In a report of 3 male adolescents with PWS subjected to MGB, an effective weight reduction, a 79\% excess weight loss two years after surgery, without need for revision surgery was observed [83]. Similarly, 3 Chinese subjects with PWS underwent bariatric surgery (2 SG and $1 \mathrm{MGB}$ ) and after a median followup of 33 months a mean weight loss and percentage of excessive weight loss at 2 years of $32.5 \mathrm{~kg}(24.9-38.3 \mathrm{~kg})$ and of $63.2 \%$ (range $50.5-86.2 \%$ ), respectively, were observed, without major complication [3]. Therefore bariatric surgery, however considering its implications and risks, can be a therapeutic strategy in case of severe obesity and failure of other weight loss interventions in the PWS subject.

\section{Conclusion}

Obesity represents one of the main complications of PWS. It predisposes to the risk of developing T2DM, dyslipidemia and cardiovascular events, mostly at a young age. GH treatment along with lifestyle interventions represent a promising approach to prevent the development of obesity in these patients. However, when obesity occurs in adulthood, the use of metformin, GLP-1RAs and naltrexone-bupropion along with lifestyle interventions have been reported to have positive effects. Data coming from on-going trials are needed to open new therapeutical scenarios in the management of obesity in PWS.

Acknowledgements We thank all participants for their contribution to our study and the reviewers for the suggestions provided.

Funding Open access funding provided by Università degli Studi di Napoli Federico II within the CRUI-CARE Agreement. This research did not receive any specific Grant from funding agencies in the public, commercial, or not-for-profit sectors.

\section{Declarations}

Conflict of interest All authors declare no conflict of interests.

Research involving human participants and/or animals The authors have nothing to disclose. This research did not receive any specific grant from funding agencies in the public, commercial, or notfor-profit sectors. As this is a review, I don't think it is necessary to add others since no human or animal studies have been conducted.

Informed consent For this type of study, formal consent is not required.

Open Access This article is licensed under a Creative Commons Attribution 4.0 International License, which permits use, sharing, adaptation, distribution and reproduction in any medium or format, as long as you give appropriate credit to the original author(s) and the source, provide a link to the Creative Commons licence, and indicate if changes were made. The images or other third party material in this article are included in the article's Creative Commons licence, unless indicated otherwise in a credit line to the material. If material is not included in the article's Creative Commons licence and your intended use is not permitted by statutory regulation or exceeds the permitted use, you will need to obtain permission directly from the copyright holder. To view a copy of this licence, visit http://creativecommons.org/licenses/by/4.0/.

\section{References}

1. Ali KF, Shukla AP, Aronne LJ (2016) Bupropion-SR plus naltrexone-SR for the treatment of mild-to-moderate obesity. Expert Rev Clin Pharmacol 9:27-34

2. Allas S, Caixas A, Poitou C, Coupaye M, Thuilleaux D, Lorenzini F, Diene G, Crino A, Illouz F, Grugni G et al (2018) AZP-531, an unacylated ghrelin analog, improves food-related behavior in patients with Prader-Willi syndrome: a randomized placebo-controlled trial. PLoS ONE 13:e0190849

3. Alqahtani AR, Elahmedi MO, Al Qahtani AR, Lee J, Butler MG (2016) Laparoscopic sleeve gastrectomy in children and adolescents with Prader-Willi syndrome: a matched-control study. Surg Obes Relat Dis 12:100-110

4. Aman LCS, Manning KE, Whittington JE, Holland AJ (2018) Mechanistic insights into the genetics of affective psychosis from Prader-Willi syndrome. Lancet Psychiatry 5:370-378

5. American Diabetes A (2019) 9. Pharmacologic approaches to glycemic treatment: Standards of Medical Care in Diabetes-2019. Diabetes Care 42:S90-S102 
6. American Diabetes A (2020) 9. Pharmacologic approaches to glycemic treatment: Standards of Medical Care in Diabetes-2020. Diabetes Care 43:S98-S110

7. American Diabetes A (2020) 2. Classification and diagnosis of diabetes: Standards of Medical Care in Diabetes-2020. Diabetes Care 43:S14-S31

8. Bakker NE, Kuppens RJ, Siemensma EP, Lind T-d, van Wijngaarden RF, Festen DA, Bindels-de Heus GC, Bocca G, Haring DA, Hoorweg-Nijman JJ, Houdijk EC et al (2013) Eight years of growth hormone treatment in children with Prader-Willi syndrome: maintaining the positive effects. J Clin Endocrinol Metab 98:4013-4022

9. Barrea L, Pugliese G, de Alteriis G, Colao A, Savastano S, Muscogiuri G (2020) Phase angle: could be an easy tool to detect low-grade systemic inflammation in adults affected by PraderWilli syndrome? Nutrients 12:2065

10. Barrea L, Muscogiuri G, Pugliese G, Aprano S, de Alteriis G, Di Somma C, Colao A, Savastano S (2020) The Sun's vitamin in adult patients affected by Prader-Willi syndrome. Nutrients 12:1132

11. Basheer R, Jalal MJ, Gomez R (2016) An unusual case of adolescent type 2 diabetes mellitus: Prader-Willi syndrome. J Family Med Prim Care 5:181-183

12. Beauloye V, Diene G, Kuppens R, Zech F, Winandy C, Molinas C, Faye S, Kieffer I, Beckers D, Nergardh R et al (2016) High unacylated ghrelin levels support the concept of anorexia in infants with Prader-Willi syndrome. Orphanet J Rare Dis 11:56

13. Bedogni G, Grugni G, Tringali G, Marazzi N, Sartorio A (2015) Does segmental body composition differ in women with PraderWilli syndrome compared to women with essential obesity? J Endocrinol Invest 38:957-961

14. Bekx MT, Carrel AL, Shriver TC, Li Z, Allen DB (2003) Decreased energy expenditure is caused by abnormal body composition in infants with Prader-Willi syndrome. J Pediatr 143:372-376

15. Benjamin E, Buot-Smith T (1993) Naltrexone and fluoxetine in Prader-Willi syndrome. J Am Acad Child Adolesc Psychiatry 32:870-873

16. Bittel DC, Butler MG (2005) Prader-Willi syndrome: clinical genetics, cytogenetics and molecular biology. Expert Rev Mol Med 7:1-20

17. Bizzarri C, Rigamonti AE, Luce A, Cappa M, Cella SG, Berini J, Sartorio A, Muller EE, Salvatoni A (2010) Children with PraderWilli syndrome exhibit more evident meal-induced responses in plasma ghrelin and peptide YY levels than obese and lean children. Eur J Endocrinol 162:499-505

18. Brambilla P, Crino A, Bedogni G, Bosio L, Cappa M, Corrias A, Delvecchio M, Di Candia S, Gargantini L, Grechi E et al (2011) Metabolic syndrome in children with Prader-Willi syndrome: the effect of obesity. Nutr Metab Cardiovasc Dis 21:269-276

19. Butler MG (2006) Management of obesity in Prader-Willi syndrome. Nat Clin Pract Endocrinol Metab 2:592-593

20. Butler MG, Swift LL, Hill JO (1990) Fasting plasma lipid, glucose, and insulin levels in Prader-Willi syndrome and obese individuals. Dysmorphol Clin Genet 4:23-26

21. Butler MG, Bittel DC, Talebizadeh Z (2004) Plasma peptide YY and ghrelin levels in infants and children with Prader-Willi syndrome. J Pediatr Endocrinol Metab 17:1177-1184

22. Butler MG, Moore J, Morawiecki A, Nicolson M (1998) Comparison of leptin protein levels in Prader-Willi syndrome and control individuals. Am J Med Genet 75:7-12

23. Candler T, McGregor D, Narayan K, Moudiotis C, Burren CP (2020) Improvement in glycaemic parameters using SGLT-2 inhibitor and GLP-1 agonist in combination in an adolescent with diabetes mellitus and Prader-Willi syndrome: a case report. J Pediatr Endocrinol Metab 33:951-955
24. Carrel AL, Myers SE, Whitman BY, Eickhoff J, Allen DB (2010) Long-term growth hormone therapy changes the natural history of body composition and motor function in children with PraderWilli syndrome. J Clin Endocrinol Metab 95:1131-1136

25. Cassidy SB, Schwartz S, Miller JL, Driscoll DJ (2012) PraderWilli syndrome. Genet Med 14:10-26

26. Castner DM, Tucker JM, Wilson KS, Rubin DA (2014) Patterns of habitual physical activity in youth with and without PraderWilli syndrome. Res Dev Disabil 35:3081-3088

27. Cataletto M, Angulo M, Hertz G, Whitman B (2011) PraderWilli syndrome: a primer for clinicians. Int J Pediatr Endocrinol 2011:12

28. Cheang JY, Moyle PM (2018) Glucagon-like peptide-1 (GLP1)-based therapeutics: current status and future opportunities beyond type 2 diabetes. ChemMedChem 13:662-671

29. Consoli A, Cabal Berthoumieu S, Raffin M, Thuilleaux D, Poitou C, Coupaye M, Pinto G, Lebbah S, Zahr N, Tauber M et al (2019) Effect of topiramate on eating behaviours in Prader-Willi syndrome: TOPRADER double-blind randomised placebo-controlled study. Transl Psychiatry 9:274

30. Crino A, Grugni G (2020) Update on diabetes mellitus and glucose metabolism alterations in Prader-Willi syndrome. Curr Diab Rep 20:7

31. Crino A, Fintini D, Bocchini S, Grugni G (2018) Obesity management in Prader-Willi syndrome: current perspectives. Diabetes Metab Syndr Obes 11:579-593

32. Damen L, Grootjen LN, Donze SH, Juriaans AF, de Graaff LCG, van der Velden J, Hokken-Koelega ACS (2020) Three years of growth hormone treatment in young adults with Prader-Willi syndrome previously treated with growth hormone in childhood: effects on glucose homeostasis and metabolic syndrome. Clin Endocrinol (Oxf). 93:439-448

33. Deal CL, Tony M, Hoybye C, Allen DB, Tauber M, Christiansen JS, Growth Hormone in Prader-Willi Syndrome Clinical Care Guidelines Workshop P (2013) Growth Hormone Research Society Workshop summary: consensus guidelines for recombinant human growth hormone therapy in PraderWilli syndrome. J Clin Endocrinol Metab 98:E1072-1087

34. DelParigi A, Tschop M, Heiman ML, Salbe AD, Vozarova B, Sell SM, Bunt JC, Tataranni PA (2002) High circulating ghrelin: a potential cause for hyperphagia and obesity in PraderWilli syndrome. J Clin Endocrinol Metab 87:5461-5464

35. Diene G, Mimoun E, Feigerlova E, Caula S, Molinas C, Grandjean H, Tauber M, French Reference Centre for PWS (2010) Endocrine disorders in children with Prader-Willi syndromedata from 142 children of the French database. Horm Res Paediatr 74:121-128

36. Dimitropoulos A, Schultz RT (2008) Food-related neural circuitry in Prader-Willi syndrome: response to high- versus lowcalorie foods. J Autism Dev Disord 38:1642-1653

37. Erdie-Lalena CR, Holm VA, Kelly PC, Frayo RS, Cummings DE (2006) Ghrelin levels in young children with Prader-Willi syndrome. J Pediatr 149:199-204

38. Esposito K, Ciotola M, Maiorino MI, Giugliano D (2008) Lifestyle approach for type 2 diabetes and metabolic syndrome. Curr Atheroscler Rep 10:523-528

39. Feigerlova E, Diene G, Conte-Auriol F, Molinas C, Gennero I, Salles JP, Arnaud C, Tauber M (2008) Hyperghrelinemia precedes obesity in Prader-Willi syndrome. J Clin Endocrinol Metab 93:2800-2805

40. Felix G, Kossoff E, Barron B, Krekel C, Testa EG, Scheimann A (2020) The modified Atkins diet in children with PraderWilli syndrome. Orphanet J Rare Dis 15:135

41. Festen DA, Wevers M, Lindgren AC, Bohm B, Otten BJ, Wit JM, Duivenvoorden HJ, Hokken-Koelega AC (2008) Mental and motor development before and during growth hormone 
treatment in infants and toddlers with Prader-Willi syndrome. Clin Endocrinol (Oxf) 68:919-925

42. Fidler MC, Sanchez M, Raether B, Weissman NJ, Smith SR, Shanahan WR, Anderson CM, Group BCT 2011 (2011) A oneyear randomized trial of lorcaserin for weight loss in obese and overweight adults: the BLOSSOM trial. J Clin Endocrinol Metab 96:3067-3077

43. Fillion M, Deal C, Van Vliet G (2009) Retrospective study of the potential benefits and adverse events during growth hormone treatment in children with Prader-Willi syndrome. J Pediatr 154:230-233

44. Fintini D, Grugni G, Brufani C, Bocchini S, Cappa M, Crino A (2014) Use of GLP-1 receptor agonists in Prader-Willi syndrome: report of six cases. Diabetes Care 37:e76-77

45. Goldstone AP, Holland AJ, Butler JV, Whittington JE (2012) Appetite hormones and the transition to hyperphagia in children with Prader-Willi syndrome. Int J Obes (Lond) 36:1564-1570

46. Goldstone AP, Holland AJ, Hauffa BP, Hokken-Koelega AC, Tauber M, Speakers Contributors at the Second Expert Meeting of the Comprehensive Care of Patients with PWS (2008) Recommendations for the diagnosis and management of Prader-Willi syndrome. J Clin Endocrinol Metab 93:4183-4197

47. Goldstone AP, Brynes AE, Thomas EL, Bell JD, Frost G, Holland A, Ghatei MA, Bloom SR (2002) Resting metabolic rate, plasma leptin concentrations, leptin receptor expression, and adipose tissue measured by whole-body magnetic resonance imaging in women with Prader-Willi syndrome. Am J Clin Nutr 75:468-475

48. Goldstone AP, Thomas EL, Brynes AE, Bell JD, Frost G, Saeed N, Hajnal JV, Howard JK, Holland A, Bloom SR (2001) Visceral adipose tissue and metabolic complications of obesity are reduced in Prader-Willi syndrome female adults: evidence for novel influences on body fat distribution. J Clin Endocrinol Metab 86:4330-4338

49. Goldstone AP, Thomas EL, Brynes AE, Castroman G, Edwards R, Ghatei MA, Frost G, Holland AJ, Grossman AB, Korbonits $M$ et al (2004) Elevated fasting plasma ghrelin in Prader-Willi syndrome adults is not solely explained by their reduced visceral adiposity and insulin resistance. J Clin Endocrinol Metab 89:1718-1726

50. Gourash L, Forster J (2009) Regulation of weight in Prader-Willi syndrome: theoretical and practical considerations

51. Greig SL, Keating GM (2015) Naltrexone ER/bupropion ER: a review in obesity management. Drugs 75:1269-1280

52. Grugni G, Crino A, Bosio L, Corrias A, Cuttini M, De Toni T, Di Battista E, Franzese A, Gargantini L, Greggio N et al (2008) The Italian National Survey for Prader-Willi syndrome: an epidemiologic study. Am J Med Genet A 146A:861-872

53. Gumus Balikcioglu P, Balikcioglu M, Muehlbauer MJ, Purnell JQ, Broadhurst D, Freemark M, Haqq AM (2015) Macronutrient regulation of ghrelin and peptide $\mathrm{YY}$ in pediatric obesity and Prader-Willi syndrome. J Clin Endocrinol Metab 100:3822-3831

54. Haqq AM, Muehlbauer MJ, Newgard CB, Grambow S, Freemark M (2011) The metabolic phenotype of Prader-Willi syndrome (PWS) in childhood: heightened insulin sensitivity relative to body mass index. J Clin Endocrinol Metab 96:E225-232

55. Haqq AM, Farooqi IS, O'Rahilly S, Stadler DD, Rosenfeld RG, Pratt KL, LaFranchi SH, Purnell JQ (2003) Serum ghrelin levels are inversely correlated with body mass index, age, and insulin concentrations in normal children and are markedly increased in Prader-Willi syndrome. J Clin Endocrinol Metab 88:174-178

56. Hauber M, Stratmann B, Hoedebeck-Stuntebeck N, Tschoepe D (2013) Medical management for adults with Prader-Willi syndrome. Metab Syndr Relat Disord 11:392-396
57. Hedgeman E, Ulrichsen SP, Carter S, Kreher NC, Malobisky KP, Braun MM, Fryzek J, Olsen MS (2017) Long-term health outcomes in patients with Prader-Willi Syndrome: a nationwide cohort study in Denmark. Int J Obes (Lond) 41:1531-1538

58. Heksch R, Kamboj M, Anglin K, Obrynba K (2017) Review of Prader-Willi syndrome: the endocrine approach. Transl Pediatr 6:274-285

59. Holsen LM, Zarcone JR, Brooks WM, Butler MG, Thompson TI, Ahluwalia JS, Nollen NL, Savage CR (2006) Neural mechanisms underlying hyperphagia in Prader-Willi syndrome. Obesity (Silver Spring) 14:1028-1037

60. Holsen LM, Savage CR, Martin LE, Bruce AS, Lepping RJ, Ko E, Brooks WM, Butler MG, Zarcone JR, Goldstein JM (2012) Importance of reward and prefrontal circuitry in hunger and satiety: Prader-Willi syndrome vs simple obesity. Int J Obes (Lond) 36:638-647

61. Hor A, Purtell L (2016) Influence of naltrexone/bupropion combination treatment on body mass index in Prader-Willi Syndrome Re: "Prader-Willi syndrome, management of impulsivity, and hyperphagia in an adolescent" by Puri et al. J Child Adolesc Psychopharmacol 26:854

62. Hoybye C, Bruun JM, Richelsen B, Flyvbjerg A, Frystyk J (2004) Serum adiponectin levels in adults with Prader-Willi syndrome are independent of anthropometrical parameters and do not change with GH treatment. Eur J Endocrinol 151:457-461

63. Hurren BJ, Flack NA (2016) Prader-Willi syndrome: a spectrum of anatomical and clinical features. Clin Anat 29:590-605

64. Irizarry KA, Mager DR, Triador L, Muehlbauer MJ, Haqq AM, Freemark M (2019) Hormonal and metabolic effects of carbohydrate restriction in children with Prader-Willi syndrome. Clin Endocrinol (Oxf) 90:553-561

65. Kato E, Kimura M, Okuda T, Toyoda M, Fukagawa M (2019) Behavior modification maintenance with long-term blood glucose and weight management in Prader-Willi syndrome complicated with diabetes: team management approach combined with pharmacological treatment. Case Rep Med 2019:6129019

66. Khan MJ, Gerasimidis K, Edwards CA, Shaikh MG (2018) Mechanisms of obesity in Prader-Willi syndrome. Pediatr Obes 13:3-13

67. Kojima M, Kangawa K (2010) Ghrelin: from gene to physiological function. Results Probl Cell Differ 50:185-205

68. Kuppens RJ, Diene G, Bakker NE, Molinas C, Faye S, Nicolino M, Bernoux D, Delhanty PJ, van der Lely AJ, Allas S et al (2015) Elevated ratio of acylated to unacylated ghrelin in children and young adults with Prader-Willi syndrome. Endocrine 50:633-642

69. Kweh FA, Miller JL, Sulsona CR, Wasserfall C, Atkinson M, Shuster JJ, Goldstone AP, Driscoll DJ (2015) Hyperghrelinemia in Prader-Willi syndrome begins in early infancy long before the onset of hyperphagia. Am J Med Genet A 167A:69-79

70. Lacroix D, Moutel S, Coupaye M, Huvenne H, Faucher P, Pelloux V, Rouault C, Bastard JP, Cagnard N, Dubern B et al (2015) Metabolic and adipose tissue signatures in adults with PraderWilli syndrome: a model of extreme adiposity. J Clin Endocrinol Metab 100:850-859

71. Lafortuna CL, Minocci A, Capodaglio P, Gondoni LA, Sartorio A, Vismara L, Rizzo G, Grugni G (2014) Skeletal muscle characteristics and motor performance after 2-year growth hormone treatment in adults with Prader-Willi syndrome. J Clin Endocrinol Metab 99:1816-1824

72. Lamb AS, Johnson WM (1987) Premature coronary artery atherosclerosis in a patient with Prader-Willi syndrome. Am J Med Genet 28:873-880

73. Lindgren AC, Marcus C, Skwirut C, Elimam A, Hagenas L, Schalling M, Anvret M, Lonnqvist F (1997) Increased leptin messenger RNA and serum leptin levels in children with 
Prader-Willi syndrome and nonsyndromal obesity. Pediatr Res 42:593-596

74. Lloret-Linares C, Faucher P, Coupaye M, Alili R, Green A, Basdevant A, Clement K, Poitou C (2013) Comparison of body composition, basal metabolic rate and metabolic outcomes of adults with Prader-Willi syndrome or lesional hypothalamic disease, with primary obesity. Int J Obes (Lond) 37:1198-1203

75. Malin SK, Kashyap SR (2014) Effects of metformin on weight loss: potential mechanisms. Curr Opin Endocrinol Diabetes Obes 21:323-329

76. McCandless SE, Committee on G (2011) Clinical report-health supervision for children with Prader-Willi syndrome. Pediatrics 127:195-204

77. Miller JL, Linville TD, Dykens EM (2014) Effects of metformin in children and adolescents with Prader-Willi syndrome and early-onset morbid obesity: a pilot study. J Pediatr Endocrinol Metab 27:23-29

78. Miller JL, Lynn CH, Shuster J, Driscoll DJ (2013) A reducedenergy intake, well-balanced diet improves weight control in children with Prader-Willi syndrome. J Hum Nutr Diet 26:2-9

79. Miller JL, Lynn CH, Driscoll DC, Goldstone AP, Gold JA, Kimonis V, Dykens E, Butler MG, Shuster JJ, Driscoll DJ (2011) Nutritional phases in Prader-Willi syndrome. Am J Med Genet A 155A:1040-1049

80. Mogul HR, Lee PD, Whitman BY, Zipf WB, Frey M, Myers S, Cahan M, Pinyerd B, Southren AL (2008) Growth hormone treatment of adults with Prader-Willi syndrome and growth hormone deficiency improves lean body mass, fractional body fat, and serum triiodothyronine without glucose impairment: results from the United States multicenter trial. J Clin Endocrinol Metab 93:1238-1245

81. Motaghedi R, Lipman EG, Hogg JE, Christos PJ, Vogiatzi MG, Angulo MA (2011) Psychiatric adverse effects of rimonobant in adults with Prader-Willi syndrome. Eur J Med Genet 54:14-18

82. Muscogiuri G, Formoso G, Pugliese G, Ruggeri RM, Scarano E, Colao A, Restare (2019) Prader-Willi syndrome: an uptodate on endocrine and metabolic complications. Rev Endocr Metab Disord 20:239-250

83. Musella M, Milone M, Leongito M, Maietta P, Bianco P, Pisapia A (2014) The mini-gastric bypass in the management of morbid obesity in Prader-Willi syndrome: a viable option? J Invest Surg 27:102-105

84. Myers SE, Whitman BY, Carrel AL, Moerchen V, Bekx MT, Allen DB (2007) Two years of growth hormone therapy in young children with Prader-Willi syndrome: physical and neurodevelopmental benefits. Am J Med Genet A 143A:443-448

85. Ostlund RE Jr, Yang JW, Klein S, Gingerich R (1996) Relation between plasma leptin concentration and body fat, gender, diet, age, and metabolic covariates. J Clin Endocrinol Metab 81:3909-3913

86. Oto Y, Tanaka Y, Abe Y, Obata K, Tsuchiya T, Yoshino A, Murakami N, Nagai T (2014) Exacerbation of BMI after cessation of growth hormone therapy in patients with Prader-Willi syndrome. Am J Med Genet A 164A:671-675

87. Padwal RS, Majumdar SR (2007) Drug treatments for obesity: orlistat, sibutramine, and rimonabant. Lancet 369:71-77

88. Pagano C, Marin O, Calcagno A, Schiappelli P, Pilon C, Milan G, Bertelli M, Fanin E, Andrighetto G, Federspil G et al (2005) Increased serum resistin in adults with Prader-Willi syndrome is related to obesity and not to insulin resistance. J Clin Endocrinol Metab 90:4335-4340

89. Page SR, Nussey SS, Haywood GA, Jenkins JS (1990) Premature coronary artery disease and the Prader-Willi syndrome. Postgrad Med J 66:232-234

90. Park WH, Oh YJ, Kim GY, Kim SE, Paik KH, Han SJ, Kim AH, Chu SH, Kwon EK, Kim SW et al (2007) Obestatin is not elevated or correlated with insulin in children with Prader-Willi syndrome. J Clin Endocrinol Metab 92:229-234

91. Perez-Tilve D, Heppner K, Kirchner H, Lockie SH, Woods SC, Smiley DL, Tschop M, Pfluger P (2011) Ghrelin-induced adiposity is independent of orexigenic effects. FASEB J 25:2814-2822

92. Pijl H, Toornvliet AC, Meinders AE (1996) Serum leptin in normalweight and obese humans. N Engl J Med 334:1544

93. Pinheiro Volp AC, Esteves de Oliveira FC, Duarte Moreira Alves R, Esteves EA, Bressan J (2011) Energy expenditure: components and evaluation methods. Nutr Hosp 26:430-440

94. Prodam F, Bellone S, Grugni G, Crino A, Ragusa L, Franzese A, Di Battista E, Corrias A, Walker G, Rapa A et al (2009) Influence of age, gender, and glucose tolerance on fasting and fed acylated ghrelin in Prader-Willi syndrome. Clin Nutr 28:94-99

95. Pujol J, Blanco-Hinojo L, Esteba-Castillo S, Caixas A, Harrison BJ, Bueno M, Deus J, Rigla M, Macia D, Llorente-Onaindia J et al (2016) Anomalous basal ganglia connectivity and obsessivecompulsive behaviour in patients with Prader-Willi syndrome. J Psychiatry Neurosci 41:261-271

96. Purtell L, Sze L, Loughnan G, Smith E, Herzog H, Sainsbury A, Steinbeck K, Campbell LV, Viardot A (2011) In adults with Prader-Willi syndrome, elevated ghrelin levels are more consistent with hyperphagia than high PYY and GLP-1 levels. Neuropeptides 45:301-307

97. Reus L, van Vlimmeren LA, Staal JB, Otten BJ, Nijhuis-van der Sanden MW (2012) The effect of growth hormone treatment or physical training on motor performance in Prader-Willi syndrome: a systematic review. Neurosci Biobehav Rev 36:1817-1838

98. Rosanna Pereira AS, Geraghty ME (2009) Prader-Willi syndrome a: review for pediatric nutrition professionals. Child Obes Nutr $1: 282-287$

99. Sahebkar A, Simental-Mendia LE, Reiner Z, Kovanen PT, Simental-Mendia M, Bianconi V, Pirro M (2017) Effect of orlistat on plasma lipids and body weight: a systematic review and meta-analysis of 33 randomized controlled trials. Pharmacol Res 122:53-65

100. Salehi P, Hsu I, Azen CG, Mittelman SD, Geffner ME, Jeandron D (2017) Effects of exenatide on weight and appetite in overweight adolescents and young adults with Prader-Willi syndrome. Pediatr Obes 12:221-228

101. Sano H, Kudo E, Yamazaki T, Ito T, Hatakeyama K, Kawamura N (2020) Efficacy of sodium-glucose cotransporter 2 inhibitor with glucagon-like peptide-1 receptor agonist for the glycemic control of a patient with Prader-Willi syndrome: a case report. Clin Pediatr Endocrinol 29:81-84

102. Scheimann AO, Miller J, Glaze DG (2017) Laparoscopic sleeve gastrectomy in children and adolescents with Prader-Willi syndrome: a matched control study. Surg Obes Relat Dis 13:366

103. Scheimann AO, Butler MG, Gourash L, Cuffari C, Klish W (2008) Critical analysis of bariatric procedures in Prader-Willi syndrome. J Pediatr Gastroenterol Nutr 46:80-83

104. Sinnema M, Maaskant MA, van Schrojenstein Lantman-de Valk HM, van Nieuwpoort IC, Drent ML, Curfs LM, Schrander-Stumpel CT (2011) Physical health problems in adults with Prader-Willi syndrome. Am J Med Genet A 155A:2112-2124

105. Small CJ, Bloom SR (2004) Gut hormones and the control of appetite. Trends Endocrinol Metab 15:259-263

106. Sode-Carlsen R, Farholt S, Rabben KF, Bollerslev J, Schreiner T, Jurik AG, Christiansen JS, Hoybye C (2012) Growth hormone treatment in adults with Prader-Willi syndrome: the Scandinavian study. Endocrine 41:191-199

107. Steculorum SM, Collden G, Coupe B, Croizier S, Lockie S, Andrews ZB, Jarosch F, Klussmann S, Bouret SG (2015) Neonatal ghrelin programs development of hypothalamic feeding circuits. J Clin Invest 125:846-858 
108. Talebizadeh Z, Butler MG (2005) Insulin resistance and obesityrelated factors in Prader-Willi syndrome: comparison with obese subjects. Clin Genet 67:230-239

109. Talebizadeh Z, Kibiryeva N, Bittel DC, Butler MG (2005) Ghrelin, peptide YY and their receptors: gene expression in brain from subjects with and without Prader-Willi syndrome. Int J Mol Med 15:707-711

110. Tanaka Y, Abe Y, Oto Y, Itabashi H, Shiraishi M, Yoshino A, Obata K, Murakami N, Nagai T (2013) Characterization of fat distribution in Prader-Willi syndrome: relationships with adipocytokines and influence of growth hormone treatment. Am J Med Genet A 161A:27-33

111. Tauber M, Conte Auriol F, Moulin P, Molinas C, Delagnes V, Salles JP (2004) Hyperghrelinemia is a common feature of PraderWilli syndrome and pituitary stalk interruption: a pathophysiological hypothesis. Horm Res 62:49-54

112. Tauber M, Coupaye M, Diene G, Molinas C, Valette M, Beauloye V (2019) Prader-Willi syndrome: a model for understanding the ghrelin system. J Neuroendocrinol 31:e12728

113. Tsuchiya T, Oto Y, Ayabe T, Obata K, Murakami N, Nagai T (2011) Characterization of diabetes mellitus in Japanese PraderWilli syndrome. Clin Pediatr Endocrinol 20:33-38
114. Zhang JV, Ren PG, Avsian-Kretchmer O, Luo CW, Rauch R, Klein C, Hsueh AJ (2005) Obestatin, a peptide encoded by the ghrelin gene, opposes ghrelin's effects on food intake. Science 310:996-999

115. Zhang Y, Wang J, Zhang G, Zhu Q, Cai W, Tian J, Zhang YE, Miller JL, Wen X, Ding M et al (2015) The neurobiological drive for overeating implicated in Prader-Willi syndrome. Brain Res $1620: 72-80$

116. Zlotkin SH, Fettes IM, Stallings VA (1986) The effects of naltrexone, an oral beta-endorphin antagonist, in children with the Prader-Willi syndrome. J Clin Endocrinol Metab 63:1229-1232

Publisher's Note Springer Nature remains neutral with regard to jurisdictional claims in published maps and institutional affiliations. 